\title{
NF-kB-inducing kinase controls lymphocyte and osteoclast activities in inflammatory arthritis
}

\author{
Kunihiko Aya, ${ }^{1,2}$ Muhammad Alhawagri, ${ }^{3}$ Amanda Hagen-Stapleton, ${ }^{3}$ Hideki Kitaura, ${ }^{1}$ \\ Osami Kanagawa, ${ }^{1}$ and Deborah Veis Novack ${ }^{1,3}$
}

1Department of Pathology and Immunology and 2Department of Pediatrics, Okayama University Graduate School of Medicine and Dentistry, Okayama, Japan. ${ }^{3}$ Division of Bone and Mineral Diseases, Department of Medicine, Washington University School of Medicine, St. Louis, Missouri, USA.

\begin{abstract}
NF- $\kappa B$ is an important component of both autoimmunity and bone destruction in RA. NF- $\kappa B$-inducing kinase (NIK) is a key mediator of the alternative arm of the NF- $\kappa B$ pathway, which is characterized by the nuclear translocation of RelB/p52 complexes. Mice lacking functional NIK have no peripheral lymph nodes, defective $B$ and $T$ cells, and impaired receptor activator of NF- $\kappa B$ ligand-stimulated osteoclastogenesis. We investigated the role of NIK in murine models of inflammatory arthritis using $\mathrm{Nik}^{-/-}$mice. The serum transfer arthritis model is initiated by preformed antibodies and required only intact neutrophil and complement systems in recipients. While $\mathrm{Ni}^{-/-}$mice had inflammation equivalent to that of $\mathrm{Nik}^{+/+}$controls, they showed significantly less periarticular osteoclastogenesis and less bone erosion. In contrast, $\mathrm{Nik}^{-/-}$mice were completely resistant to antigen-induced arthritis (AIA), which requires intact antigen presentation and lymphocyte function but not lymph nodes. Additionally, transfer of $\mathrm{Ni}^{+/ /}$splenocytes or $\mathrm{T}$ cells to $\mathrm{Rag} 2^{-/-}$mice conferred susceptibility to AIA, while transfer of $\mathrm{Nik}^{-/-}$cells did not. $\mathrm{Nik}^{-/-}$mice were also resistant to a genetic, spontaneous form of arthritis, generated in mice expressing both the KRN T cell receptor and $\mathrm{H}-2^{\mathrm{g}}$. Thus, NIK is important in the immune and bone-destructive components of inflammatory arthritis and represents a possible therapeutic target for these diseases.
\end{abstract}

\section{Introduction}

RA is a chronic, joint-centered autoimmune disorder characterized by inflammation and proliferation of synovium, accompanied by erosion of underlying cartilage and bone. Although the factors initiating this disease are not fully understood, its progression can be largely attributed to the activation of lymphocyte and osteoclast (OC) lineages (1). Other forms of inflammatory arthritis, such as that accompanying psoriasis, have similar pathogenesis $(2,3)$.

Early in the course of RA, T cells localize to the synovium, where they interact with resident macrophage-like type A synoviocytes (4). In established RA, T cells represent the most abundant inflammatory cell in the joint, where they stimulate type A synoviocytes to secrete proinflammatory cytokines. In addition, $\mathrm{T}$ cells also induce B cell maturation, a necessary step in the generation of rheumatoid factors, polyclonal antibodies against the Fc domain of IgG. Additionally, antibodies with specificity for a variety of foreign antigens, as well as autoantigens, can be found in RA synovial tissue, where they activate the complement cascade, contributing to joint destruction (1). However, no single autoantibody has been found in all patients. Susceptibility to RA is also linked to particular alleles in the major histocompatibility locus, which suggests that the context of antigen presentation to lymphocytes is also important. Thus, both $\mathrm{T}$ and $\mathrm{B}$ lymphocyte activation contribute to joint inflammation and injury.

Nonstandard abbreviations used: AIA, antigen-induced arthritis; IKK $\alpha$, IKB kinase $\alpha$; LT- $\alpha$, lymphotoxin- $\alpha$; mBSA, methylated BSA: NIK, NF-KB-inducing kinase; OC, osteoclast; PTH, parathyroid hormone; RANKL, receptor activator of NF-KB ligand; STA, serum transfer arthritis; TRAP, tartrate resistant acid phosphatase. Conflict of interest: The authors have declared that no conflict of interest exists.
Degradation of bone, a major component of the crippling RA lesion, can only be accomplished by OCs, which are derived from monocytes/macrophages in the pannus (5). The critical mediators of osteoclastogenesis, M-CSF and receptor activator of NF- $\mathrm{KB}$ ligand (RANKL), are expressed by bone marrow stromal cells, osteoblast, and activated T cells. Importantly, RANKL expression by synovial fibroblastoid cells is enhanced in RA joints (6), as are other cytokines that enhance osteoclastogenesis, such as TNF- $\alpha$. Blockade of RANKL blocks bone erosion in models of adjuvant arthritis (7) or serum transfer (8). Mice expressing a human TNF- $\alpha$ transgene on a $c-f o s^{-1-}$ background completely lack functional OCs and are fully protected against bone erosion in spite of severe inflammatory arthritis (9), which confirms the central role of OCs in arthritic osteolysis.

Because the differentiation and function of $\mathrm{T}$ and $\mathrm{B}$ lymphyocytes and OCs is dependent on NF-кB $(10,11)$ and because the inflammatory milieu induces NF-кB activation in these target cells, inhibitors of NF- $\kappa \mathrm{B}$ are considered to be of potential therapeutic use in the treatment of RA (12). It is now recognized that there are 2 distinct NF-кB pathways, classical and alternative (13). The classical pathway, activated by most NF- $\kappa \mathrm{B}$-inducing cytokines, including TNF- $\alpha$ and IL-1, involves degradation of I $\mathrm{B} \alpha$ and release of active NF-кB dimers, primarily p65/p50, into the nucleus. The alternative pathway, activated by a subset of cytokines including CD40L, lymphotoxin- $\beta$ (Lt- $\beta$ ), and RANKL, is controlled by NF-кB-inducing kinase (NIK), which activates IкB kinase $\alpha$ (IKK $\alpha$ ), prompting generation of the active NF- $\kappa B$ subunit $\mathrm{p} 52$ from its precursor p100. The alternative pathway is activated in concert with the classical pathway by these cytokines, and its primary transcriptionally active nuclear complex is RelB/p52. Several studies have shown that blockade of classical NF- $\mathrm{KB}$ signaling, through the use of inhibitors 

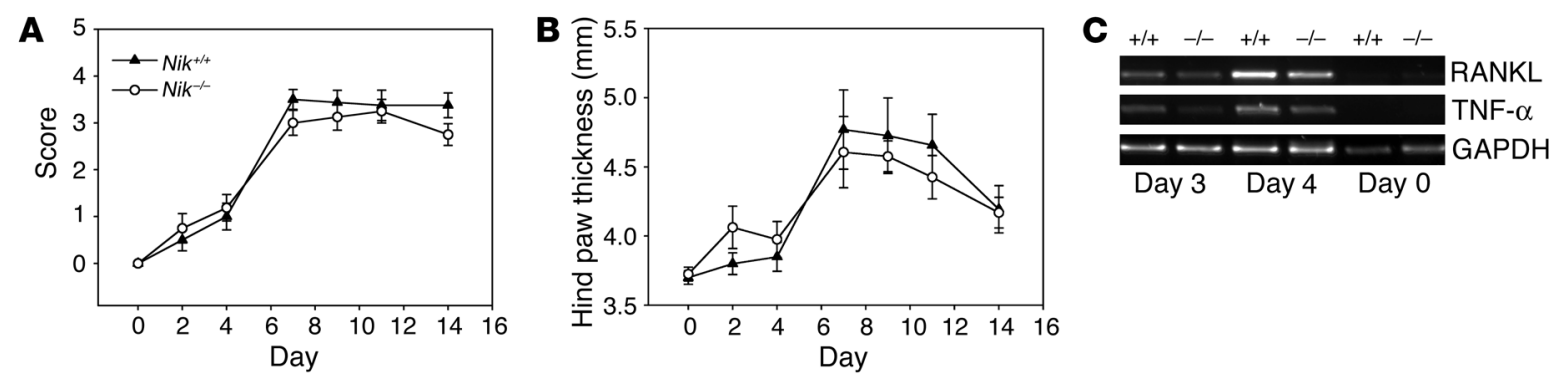

Figure 1

Equivalent inflammatory response to serum transfer arthritis. Response of $\mathrm{Nik}^{+/+}$and $\mathrm{Nik}^{-/-}$mice to arthritogenic serum was evaluated from days 0 to 14 by clinical scoring $(\mathbf{A})$ and measurement of hind paw thickness (B). Clinical scores were obtained by observation of all 4 paws, with a maximum score of 4 indicating whole-paw redness and swelling in all 4 . Hind paw thickness was measured by digital gauge at the ankle, and the sum of the data for both paws was plotted. Graphs show mean \pm SEM at each data point for 8 mice. There were no significant differences $(P<0.05)$ in either parameter between $\mathrm{Nik}^{+/+}$and $\mathrm{Nik}^{-/-}$mice. (C) Semiquantitative RT-PCR analysis of RNA derived from hind paws at days 0 , 3 , and 4 shows that RANKL and TNF- $\alpha$ are both induced by injection of arthritogenic serum in $\mathrm{Nik}^{+/+}$and $\mathrm{Nik}^{-/-}$animals.

and in knockout mice, reduces both inflammation and bone erosion in murine models of arthritis (14-17). However, because of its central role in many normal biological processes, global inhibition of classical NF- $\kappa B$ may not be therapeutically viable. The alternative NF-кB pathway appears to be activated by a much more restricted set of signals and thus might represent a better therapeutic target. However, none of the previous studies addresses the possible role of this pathway in arthritis.

The role of the NIK/IKK $\alpha / \mathrm{p} 100 / \mathrm{p} 52$ pathway in the immune system has been established in several model systems. NIK-deficient mice lack peripheral lymph nodes and Peyer's patches, due to defects in the stromal cell response to Lt- $\beta$ (18-20). In intact NIK-deficient animals, this stromal cell abnormality also contributes to lymphocyte dysfunction, with decreased antibody production after immunization (18) and delayed clearance of pathogens $(21,22)$. Bone marrow transplant experiments have demonstrated cell-autonomous defects in lymphocytes, including decreased proliferation of both $\mathrm{B}$ and $\mathrm{T}$ cells and reduced antibody production, although the degree of dysfunction depends on the mode of stimulation and the specific function assayed (23). Studies using lymphocytes with defects in the molecules downstream of NIK have confirmed the important role of this pathway in B cell maturation $(24,25)$. The reduced ability of NIK-deficient mice to clear pathogens suggests that NIK is also important in T cell function. However, the cell-autonomous effect of NIK deficiency in T cells has not been explored in disease models.

We have previously shown that $\mathrm{Nik}^{-/-}$mice have normal basal bone structure but are resistant to RANKL- or parathyroid hormone-stimulated (PTH-stimulated) osteoclastogenesis (26). Additionally, $\mathrm{Nik}^{-/-}$precursors are highly resistant to RANKLinduced osteoclastogenesis in vitro. Although RANKL-naive precursors have intact classical NF- $\mathrm{KB}$ signaling, treatment with RANKL induces accumulation of the IKB-like $\mathrm{p} 100$ protein, which leads to inhibition of both the classical and alternative pathways. Recently it has been shown that $I \mathrm{KK \alpha}^{-/-}$mice have a similar OC defect (27). In contrast, $N f k b 1^{-/-} N f k b 2^{-/-}$mice, which lack both the p50 and p52 NF- $\mathrm{kB}$ subunits, are osteopetrotic and have no OCs, presumably due to an earlier and more profound blockade

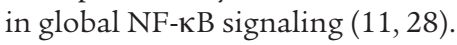

In this article, we examine the importance of NIK in the periarticular bone erosion that accompanies inflammatory arthritis using the lymphocyte-independent serum transfer model (29).
Additionally, we explore the role of NIK in the induction of inflammatory arthritis using 2 models dependent on lymphocyte function, antigen-induced arthritis (AIA) (30) and the spontaneous $\mathrm{K} / \mathrm{BxN}(\mathrm{KRN} \times \mathrm{NOD})$ model (31). We find that NIK is critical for both the induction of inflammation by lymphocytes and for bone erosion by OCs.

\section{Results}

Role of NIK in bone erosion. Having previously shown that $\mathrm{Nik}^{-/-}$mice are resistant to induction of osteoclastogenesis by RANKL and PTH in vivo (26), we set out to determine whether this would hold true in a model of human disease such as RA. We chose a variant of the well-described serum transfer model in which serum from $\mathrm{K} / \mathrm{BxN}$ mice is injected into naive recipients. $\mathrm{K} / \mathrm{BxN}$ mice experience a spontaneous autoimmune arthritis mediated by $\mathrm{T}$ cell and $\mathrm{B}$ cell interactions resulting in the production of pathogenic anti-glucose-6-phosphate isomerase antibodies (32). Transfer of serum, which contains antibodies and TNF- $\alpha$, from arthritic $\mathrm{K} / \mathrm{BxN}$ mice results in the rapid development in recipients of joint inflammation resembling the spontaneous $\mathrm{K} / \mathrm{BxN}$ arthritis both clinically and histologically (29). However, this serum transfer arthritis (STA) is mediated primarily by neutrophils and complement and does not require T cells and B cells in the recipient (29, 33). Thus, using STA, we could examine the role of NIK in bone erosion separate from its role in lymphocytes. Although STA can be induced in a wide variety of mouse strains, there is significant variability in the intensity of inflammation only (34). Our colony of $N i k^{? / ?}$ mice is on the $129 \mathrm{~Sv} / \mathrm{Ev}$ background, which is relatively resistant to STA, with only minimal inflammation induced in $\mathrm{Nik}^{+/+}$mice following a single injection of serum (data not shown). Therefore, $\mathrm{Nik}^{+/+}$and $\mathrm{Nik}^{-/-}$mice were injected with $\mathrm{K} / \mathrm{BxN}$ serum on days 0,2 , and 7 . Additionally, LPS was administered on day 2. The clinical score and thickness of hind paws of $\mathrm{Nik}^{-/-}$mice are very similar to those of $\mathrm{Ni}^{+/+}$mice through day 14 , with no statistically significant differences $(P<0.05)$ at any time point (Figure 1 , $A$ and $B)$. These clinical data suggest that NIK is not important for the inflammatory response in STA.

In the setting of inflammatory arthritis, osteoclastogenesis and bone erosion are induced by the production of RANKL and TNF- $\alpha$ by inflammatory and synovial cells. We therefore investigated the induction of these cytokines in the ankle joints of mice in the early phases of STA by semiquantitative RT-PCR. In both $\mathrm{Ni}^{+/+}$ 
and $\mathrm{Ni}^{-/-}$mice, RANKL and TNF- $\alpha$ messages were substantially increased above baseline (Figure 1C). This finding is in agreement with a previous study that was unable to demonstrate a role for NIK in TNF- $\alpha$ production in the context of human RA (35).

Histological sections of hind paws were stained with $\mathrm{H} \& \mathrm{E}$ and tartrate resistant acid phosphatase (TRAP), a marker of OC differentiation. In control mice, not injected with serum, the talus, calcaneus, and metatarsal bones have smooth surfaces and open joint spaces free of cells (Figure 2, A and D). OCs are confined to marrow spaces (Figure 2G, arrowheads). In $\mathrm{Nik}^{+/+}$mice (Figure 2, B and $\mathrm{E}$ ), joint spaces are narrowed, filled primarily with neutrophils and synoviocytes, and bone contours are irregular, showing pannus invasion as well as new bone formation. TRAP stains showed abundant OCs on the bone surfaces, especially in areas of pannus invasion (Figure $2 \mathrm{H}$, arrows). Although $\mathrm{Nik}^{-/-}$hind paws show a similar degree of inflammation and narrowing of joint spaces (Figure 2, C and F), only rare OCs are seen on largely smooth bone surfaces (Figure 2I, arrows). New bone formation, particularly on the dorsal tibia and plantar calcaneus, was similar in $\mathrm{Nik}^{+/+}$and $\mathrm{Nik}^{-/-}$mice (Figure 2, B and C, asterisk). Slides of the more inflamed hind paw of each animal were scored for inflammation and bone erosion, using an arbitrary scale (see Methods), by a blinded observer. While there was no difference in inflammation between the 2 groups, $\mathrm{Nik}^{-/-}$paws showed significantly less bone erosion (Figure 2J). Additionally, the number of TRAP ${ }^{+}$OCs on the bone surface, as well as adjacent to marrow spaces, was quantitated in the region shown in Figure 2, G-I. $N i k^{-/-}$paws had significantly fewer OCs in both compartments, with 4.8-fold fewer OCs on the surface (Figure $2 \mathrm{~K}$ ). In order to confirm this histological evidence of reduced bone resorption, we measured TRAP5b levels in the serum prior to, and on day 14 of, STA. While $\mathrm{Ni}^{+/+}$mice showed a significant increase in serum TRAP5b levels, Nik ${ }^{-/-}$mice did not (Figure 2L). Thus, although NIK is not required for the inflammatory response in STA, it is needed for bone erosion.

Previously we showed that isolated $\mathrm{Nik}^{-/-}$ OC precursors are resistant to RANKL-mediated osteoclastogenesis in vitro (26). Because TNF- $\alpha$ synergizes with RANKL to enhance osteoclastogenesis in wild-type cells, and TNF- $\alpha$ levels are substantially elevated in STA (Figure 1C and ref. 15), we examined the effects of TNF- $\alpha$ on $\mathrm{Nik}^{-/-}$osteoclastogenesis in vitro (Supplemental Figure 2; supplemental material available online with this article; doi:10.1172/JCI23763DS1). In the presence of NIK, addition of TNF $\alpha$ with very low levels of RANKL $(2.5 \mathrm{ng} / \mathrm{ml})$ yielded confluent sheets of TRAP ${ }^{+}$OCs. In the absence of NIK, only a few mononuclear $\mathrm{TRAP}^{+}$cells were

Figure 2 produced. Only very high doses of RANKL (150 ng/ml), which are greater than the optimal dose for wild-type osteoclastogenesis, were able to synergize with TNF- $\alpha$ to generate some multinucleated, $\mathrm{TRAP}^{+}$cells in $\mathrm{Nik}^{-/-}$cultures. The relative resistance of $\mathrm{Nik}^{-/-}$ precursors to RANKL- and TNF- $\alpha$-induced osteoclastogenesis is similar to that of $I K \mathrm{K \alpha}^{-/-}$cells (27).

Role of NIK in inflammation in AIA. Because RA in humans is an autoimmune disease mediated by the interactions of lymphocytes and APCs, we next sought to determine whether NIK was important in the induction of lymphocyte-dependent inflammatory arthritis models. AIA is induced by systemic immunization with methylated BSA (mBSA), followed by local injection of mBSA into
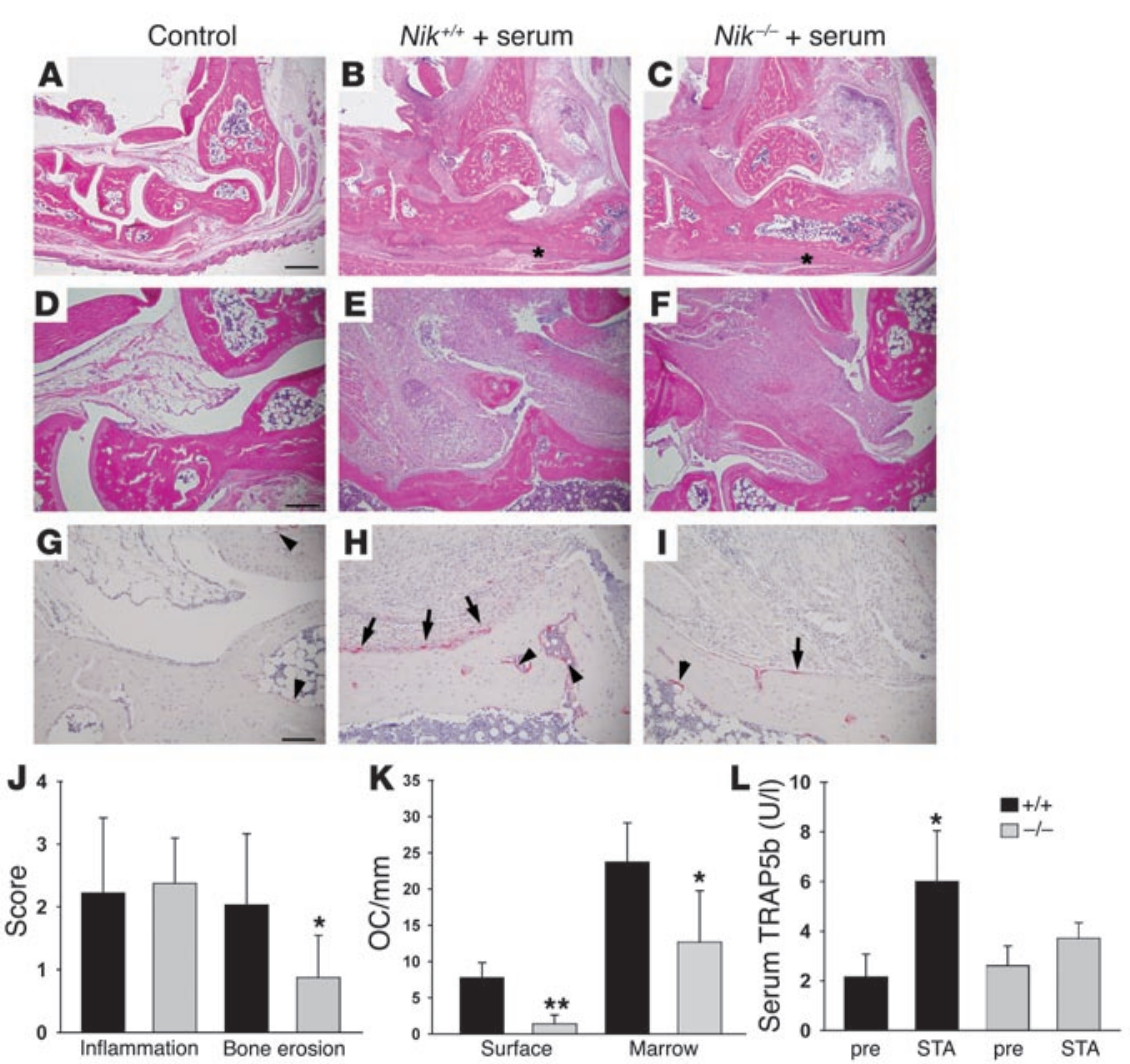

Histological evaluation of STA. Hind paws from control mice (A, D, and G) and from $\mathrm{Nik}^{+/+}(\mathbf{B}$, $\mathbf{E}$, and $\mathbf{H})$ and $\mathrm{Nik}^{-1-}(\mathbf{C}, \mathbf{F}$, and I) mice with STA at day 14 were sectioned and stained with H\&E (A-F) or TRAP (G-I). In control sections ( $\mathbf{A}$ and $\mathbf{D})$ ), bones were closely apposed, with smooth surfaces and no inflammatory infiltrate. The TRAP stain $(\mathbf{G})$ shows scattered OCs (stained red) at bone/marrow interfaces (arrowheads) but none on bone surfaces. In contrast, $\mathrm{Nik}^{+/+}$paws from serum-injected mice (B and E) had an extensive inflammatory infiltrate in the joint spaces. In the TRAP stain (H), OCs were prominent in marrow (arrowheads) and on bone surfaces (arrows), particularly where the inflammatory pannus was adjacent. In these areas, the bone surface was irregular, which indicates bone erosion. $\mathrm{Nik}^{-/-}$mice with arthritis (C and F) show an inflammatory infiltrate similar to that of $\mathrm{Nik}^{+/+}$mice. However, bone contours remain smooth. The TRAP stain (I) shows OCs within the marrow (arrowhead) but few on bone surfaces, even where adjacent to pannus (arrow). Scale bar: $500 \mu \mathrm{m}$ for A-C; 200 $\mu \mathrm{m}$ for D-F; and $100 \mu \mathrm{m}$ for $\mathbf{G}-\mathbf{I}$. (J) Histological sections were scored for inflammation (left) based on H\&E stains and for bone erosion (right) based on TRAP stains according to an arbitrary scale of $0-3$. (K) TRAP-stained sections were evaluated by histomorphometry in the regions shown in $\mathbf{H}-\mathbf{I}$. The mean number of OCs per $\mathrm{mm}( \pm \mathrm{SD})$ present on the bone surface (left) and at the marrow interface (right) is shown. ( ${ }^{\star} P<0.01 ;{ }^{* \star} P<0.00005$, $\mathrm{Nik}^{-1-}$ compared with $\mathrm{Nik}^{+/+} ; n=7-8$ per group). (L) Serum levels of TRAP5b, a form of the enzyme specific for active OCs, were determined 1 day prior to first serum injection (pre) and at day 14 (STA). ${ }^{*} P<0.01$ compared with pre-injection $\mathrm{Nik}^{+/+}$by paired Student's $t$ test; $n=4$ ) 
Table 1

Incidence of arthritis in AIA model

\begin{tabular}{|c|c|c|c|}
\hline Group & None & Mild & Severe \\
\hline $\mathrm{Nik}^{+-}$ & 0 & 1 & 6 \\
\hline $\mathrm{Nik}^{-/}$ & 8 & 1 & 0 \\
\hline$L t-\alpha^{-/-}$ & 0 & 1 & 3 \\
\hline $\mathrm{Nik}^{+/+} \rightarrow \mathrm{Rag}^{-/-}$ & 2 & 1 & 9 \\
\hline $\mathrm{Nik}^{-1-} \rightarrow \mathrm{Rag}^{-/-}$ & 7 & 1 & 0 \\
\hline $\begin{array}{l}\mathrm{Nik}^{+/+}(\mathrm{B} \text { cells })+ \\
\mathrm{Nik}^{-/-}(\mathrm{T} \text { cells }) \rightarrow \mathrm{Rag}^{-/-}\end{array}$ & 5 & 0 & 0 \\
\hline $\begin{array}{l}\left.\mathrm{Nik}^{-/-} \text {(B cells }\right)+ \\
\mathrm{Nik}^{+++}(\mathrm{T} \text { cells }) \rightarrow \text { Rag2 }^{-/-}\end{array}$ & 1 & 0 & 3 \\
\hline $\operatorname{Rag}^{-1-}$ & 2 & 0 & 0 \\
\hline
\end{tabular}

Data indicate the number of mice with a given condition. Arthritis was evaluated histologically on H\&E-stained sections. The difference between $\mathrm{Nik}^{+-}$and $\mathrm{Nik}^{-/-}$mice and between the $\mathrm{Rag}^{-/-}$transfer groups was significant $(P<0.001)$. Nik ${ }^{+/+} \rightarrow$ Rag2 $^{-/-}$, Rag2 $^{-/-}$mice injected with $\mathrm{Nik}^{+/+}$splenocytes; $\mathrm{Nik}^{-/-} \rightarrow \mathrm{Rag}^{-/-}, \mathrm{Rag}^{-/-}$mice injected with $\mathrm{Nik}^{-/-}$ splenocytes; $\mathrm{Nik}^{+/+}$(B cells) $+\mathrm{Nik}^{-/-}$(T cells) $\rightarrow \mathrm{Rag}^{-/-}, \mathrm{Rag}^{-/-}$mice injected with a mixture of $\mathrm{Nik}^{+/+} \mathrm{B}$ cells and $\mathrm{Nik}^{-1-} \mathrm{T}$ cells; $\mathrm{Nik}^{-1-}$ (B cells) $+\mathrm{Nik}^{+/+}$(T cells $) \rightarrow \mathrm{Rag}^{-/-}, \mathrm{Rag}^{-/-}$mice injected with a mixture of $\mathrm{Nik}^{-/-} \mathrm{B}$ cells and $\mathrm{Nik}^{+/+} \mathrm{T}$ cells.

a single joint space. Induction of AIA is dependent on T lymphocyte function (30), and, in contrast to collagen-induced arthritis, it can be induced in a variety of mouse strains.

$\mathrm{Nik}^{+/-}(n=7)$ and $\mathrm{Nik}^{-/-}(n=9)$ mice were immunized with mBSA and with adjuvant and pertussis toxin on days 0 and 7 and were injected with mBSA directly into the right knee joint space on day 21. As a control, left knees were injected with PBS only. All but 1 $\mathrm{Nik}^{+/-}$mouse had severe arthritis on day 32, while none of the $\mathrm{Ni}^{-/-}$ mice showed severe inflammation (Table 1 and Figure $3, \mathrm{~A}-\mathrm{C}$ ). This indicates that NIK is essential for the induction of AIA.

NIK is required for the development of lymph node stromal cells, and in its absence there are no peripheral lymph nodes. To determine whether lymph nodes, as a site of antigen presentation, are needed for the induction of AIA, we studied the lymphotoxin $\alpha^{-/-}\left(L T-\alpha^{-/-}\right)$ mouse. $L T-\alpha^{-/-}$mice also lack peripheral lymph nodes, but their lymphocyte function is intact $(36,37)$. With the same induction protocol used for $\mathrm{Nik}^{+/-}$and $\mathrm{Ni}^{-/-}$mice, 3 of $4 \mathrm{LT}-\alpha^{-/-}$mice had severe AIA, while the fourth had mild arthritis (Table 1 and Figure 3D). Therefore, the presence of lymph nodes is not required for AIA.

Next, to determine whether $\mathrm{Ni}^{-/-}$lymphocytes could mediate AIA in the presence of an intact lymph node stroma, we utilized the AIA model in the context of lymphocyte transfer. Rag2 $2^{-/}$mice have no mature $\mathrm{T}$ or B lymphocytes but an intact lymph node

\section{Figure 3}

Histological evaluation of AIA. (A) PBS-injected control joint, with a relatively acellular joint space (between arrows). (B) mBSA-injected $\mathrm{Nik}^{+/-}$ knee joint showing a severe inflammatory infiltrate (between arrows) that extends beyond the joint capsule, accompanied by bone erosion (cortical thinning; arrowhead). (C) mBSA-injected $\mathrm{Nik}^{-1-}$ knee joint resembling control joint. (D) mBSA-injected $L t-\alpha^{-/-}$joint, showing severe inflamma-

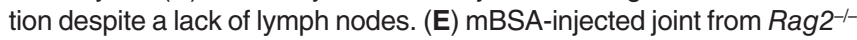
recipient of $\mathrm{Nik}^{+/+}$unfractionated splenocytes showing severe arthritis. (F) mBSA-injected joint from Rag2 ${ }^{-/-}$recipient of $\mathrm{Nik}^{-/-}$unfractionated

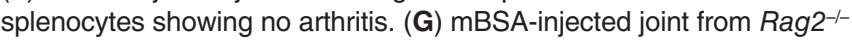
recipient of $\mathrm{Nik}^{-1-} \mathrm{T}$ cells and $\mathrm{Nik}^{+++} \mathrm{B}$ cells, showing no arthritis. $(\mathrm{H})$ mBSA-injected joint from $\mathrm{Rag}^{-1-}$ recipient of $\mathrm{Nik}^{+/+} \mathrm{T}$ cells and $\mathrm{Nik}^{-1-} \mathrm{B}$ cells, showing severe arthritis. Magnification in all panels, $\times 40$. stroma, and they are available on the same 129Sv/Ev strain as the NIK mice. Therefore, wild-type lymphocytes do not cause a graftversus-host reaction in a nonirradiated $\mathrm{Rag}^{-/-}$recipient (38). One day prior to the first mBSA immunization, at day 1 , we injected a suspension of either $\mathrm{Nik}^{+/+}$or $\mathrm{Nik}^{-/-}$splenocytes into each $\mathrm{Rag}^{-/-}$ recipient without previous irradiation. The subsequent regimen for induction of AIA was the same as before. Nine of 12 Rag $2^{-/-}$ recipients of $\mathrm{Nik}^{+/+}$splenocytes showed severe knee joint inflammation on day 32, compared with 0 of 8 recipients of $\mathrm{Nik}^{-/-}$cells $\left(P<0.0001\right.$; Table 1 and Figure 3, E and F). To ensure that $\mathrm{Nik}^{-/-}$ lymphocytes had survived for the duration of the experiment as well as $\mathrm{Nik}^{+/+}$cells, we performed flow cytometry for the T cell markers CD90 on splenocytes at the time of sacrifice (day 32). The number of $\mathrm{T}$ cells was comparable in both groups (Supplemental Figure 1). Thus, the difference in arthritis in $\mathrm{Nik}^{+/+}$and $\mathrm{Nik}^{-/-}$recipients is not due to poor migration or survival of $\mathrm{Nik}^{-/-}$cells.

We next sought to determine whether NIK deficiency in $\mathrm{T}$ and/ or B lymphocytes was responsible for the observed resistance to AIA. Therefore, we used high-speed flow sorting (MoFlo) to obtain pure (>99\% by post-sorting analysis; data not shown) populations of B and T lymphocytes from both $\mathrm{Nik}^{+/+}$and $\mathrm{Nik}^{-/-}$spleens, with B220 and CD90, respectively, as markers. We then mixed $\mathrm{Nik}^{+/+}$ B cells with $N i k^{-/-} \mathrm{T}$ cells $\left(5 \times 10^{6}\right.$ of each $)$ or $\mathrm{Nik}^{-/-} \mathrm{B}$ cells with

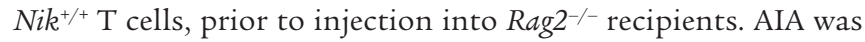
induced as before. While 0 of 5 recipients of $\mathrm{Nik}^{-/-} \mathrm{T}$ cells (mixed with $\mathrm{Nik}^{+/+} \mathrm{B}$ cells) showed histological evidence of arthritis, 3 of 4 of the recipients of $\mathrm{Nik}^{+/+} \mathrm{T}$ cells (mixed with $\mathrm{Nik}^{-/-} \mathrm{B}$ cells) had
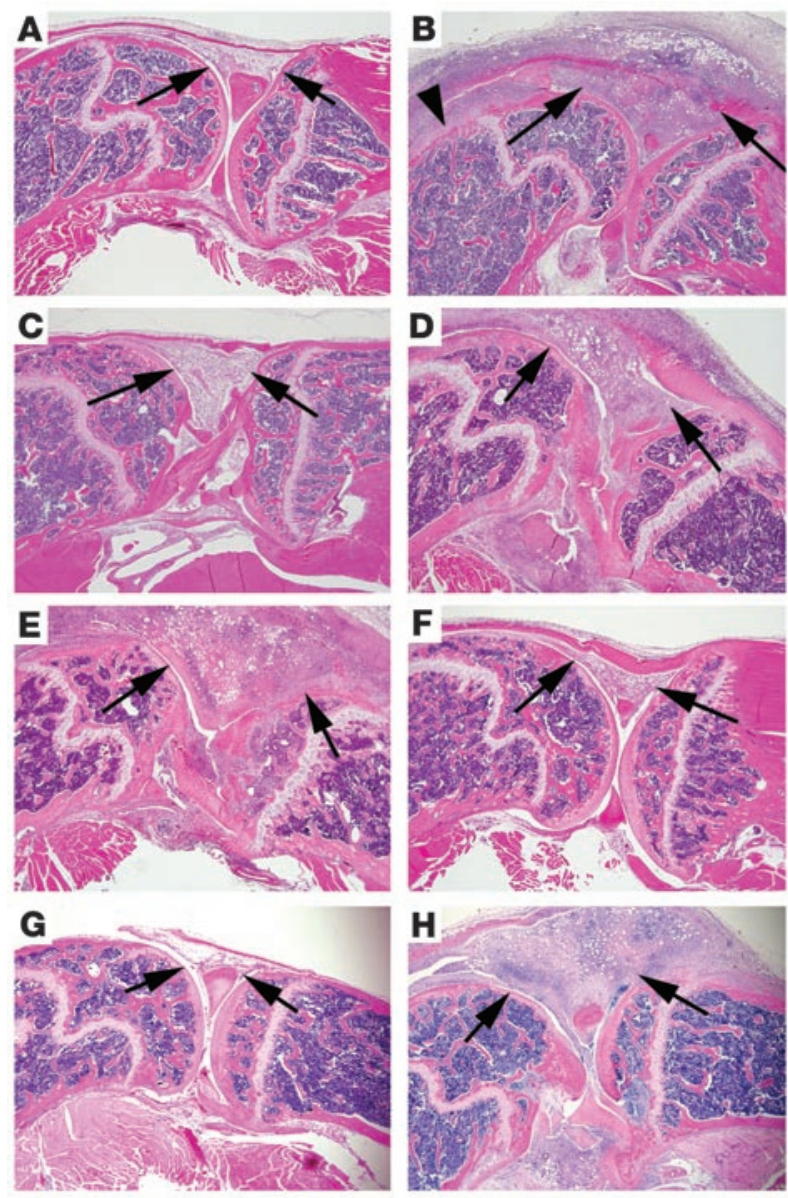
severe arthritis (Table 1 and Figure 3, G and H). As with unfractionated splenocytes, the levels of engraftment of WT and NIKdeficient $\mathrm{T}$ cells were comparable, as assessed by flow cytometry of spleen at the time of sacrifice (data not shown). Thus, NIK is required in $\mathrm{T}$ lymphocytes for induction of AIA.

Role of NIK in spontaneous $K / B x N$ arthritis. Having determined that NIK is critical in the initiation phase of an acute, antigeninduced model of arthritis, we next assessed the role of NIK in a genetic model of chronic arthritis, the $\mathrm{K} / \mathrm{BxN}$ model. To this end, we separately transferred the NIK-null allele onto the KRN $\mathrm{T}$ cell receptor-transgenic mouse and onto the $\mathrm{H}-2^{\mathrm{g} 7}$-transgenic mouse. $\mathrm{KRN}^{+} / \mathrm{H}-2^{\mathrm{g}}$ mice of all NIK genotypes were followed with paw thickness measurements from 5 weeks of age (Figure 4A). By this time, 11 of $13 \mathrm{Nik}^{+/ ?}$ mice (a group including both $\mathrm{Nik}^{+/+}$and $\mathrm{Nik}^{+/-}$mice) had red, swollen paws, with a total 4-paw thickness greater than $10.7 \mathrm{~mm}$. Nik ${ }^{-/-}$mice $(n=7)$ had no clinical signs of arthritis, and total paw thicknesses ranged from 7.5 to $9.5 \mathrm{~mm}$. By the age of $11-15$ weeks, all $\mathrm{Nik}^{+/-}$mice $(n=18)$ had clinical signs of arthritis and maximum paw measurements of 11.9 to $15 \mathrm{~mm}$. At the time of sacrifice at $11-15$ weeks, $\mathrm{Ni}^{-/-}$mice $(n=9)$ showed no clinical arthritis, and none had total paw thickness greater than $9.6 \mathrm{~mm}$. Histological analysis of both front and hind paws supports the clinical findings. $\mathrm{Ni}^{+/ ?}$ mice show extensive joint inflammation and extensive bone remodeling, with bone fusions, irregular shapes, and new bone formation (Figure 4, B and D). Only 1 of $7 \mathrm{Nik}^{-/-}$mice examined histologically showed any evidence of joint inflammation, with mild arthritis in a single paw. Other $\mathrm{Nik}^{-/-}$paws were normal (Figure 4, C and E). We conclude that NIK is required for the induction of $\mathrm{K} / \mathrm{BxN}$ arthritis.

\section{Discussion}

NF- $\kappa \mathrm{B}$ activation is a component of RA in patients (12), and it is also seen in murine models of inflammatory arthritis $(14,15$, $17,39)$. Several of these studies have also shown that blockade of

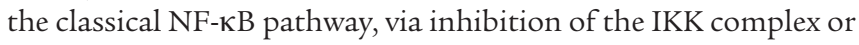
with IкB $\alpha$ superrepressor (15-17), diminishes the inflammatory response and accompanying bone loss. None of these treatments is directed at the alternative NF- $\mathrm{KB}$ pathway, and possible effects of these regimens on the alternative pathway were not addressed. Additionally no study has separated an effect on inflammation from one on bone erosion when OCs are present. In this article, we report that NIK, the primary control point for the activation for the alternative NF- $\mathrm{KB}$ pathway, is critical for both the immunemediated initiation of inflammatory arthritis and for bone erosion in the context of a robust neutrophilic inflammatory response.

Our previous studies showed that $\mathrm{Nik}^{-/-}$mice are resistant to the osteoclastogenic effects of both exogenous RANKL and PTH in vivo (26). The current data derived from the STA model, demonstrating decreased osteoclastogenesis and bone resorption, extend the pathophysiological context of NIK action to include inflammatory bone loss. Furthermore, although others have shown that inhibition of NF- $\mathrm{\kappa B}$ diminishes bone erosion in inflammatory arthritis, all of these studies have shown concomitant reductions in inflammation (15-17). Although in vitro studies showed direct effects on osteoclastogenesis with these inhibitors, the in vivo effects might have been primarily mediated via the inflammatory component, with the effect on OCs secondary to diminution of the inflammation. In contrast, we found that, even in the presence of severe inflammation, bone resorption is blocked in the absence of NIK. We have shown previously that the loss of NIK activity in the
OC lineage, but not in lymphocytes, results in defective NF-кB signaling in both the classical and alternative pathways (26). Whether this will result in a unique sensitivity of OCs, compared with other cell types, to blockade of the NIK pathway must be tested when pharmacological inhibitors of this pathway are developed.

Like RA, mBSA-induced AIA results from deposition of immune complexes in the affected joints. In order for synovial inflammation and proliferation and bone erosion to occur, $\mathrm{T}$ cells must respond to APCs, which leads to $\mathrm{B}$ cell production of antibodies in the context of a complex array of cytokines including TNF- $\alpha$, IL-1, and IL-6 (4). Both T cell transfer experiments $(30,40)$ and cell depletion experiments (41) demonstrate that $\mathrm{CD}^{+} \mathrm{T}$ cells are critical for the initiation of the inflammatory response. The complete lack of an inflammatory response in $\mathrm{Nik}^{-/-}$mice suggests an inability of NIK-deficient $\mathrm{T}$ cells to respond to mBSA. This could be due to intrinsic defects in T cells or APCs or the lack of a site for this interaction, i.e., the lack of peripheral lymph nodes in $\mathrm{Ni}^{-/-}$mice. Therefore, we assessed the susceptibility to AIA of $L t-\alpha^{-/-}$mice, which lack lymph nodes but are able to mount a high-affinity $\mathrm{T}$ cell-dependent antibody response $(36,42)$ and found no difference from wild-type mice. Thus, the presence of lymph nodes is not required for the induction of AIA. Nevertheless, the lack of lymph nodes in $\mathrm{Ni}^{-/-}$mice might contribute to their failure to respond to mBSA challenge, in combination with the lymphocyte defects $(21,23,43)$. In order to evaluate the capacity of $\mathrm{Nik}^{-/-}$cells to confer susceptibility to AIA in the presence
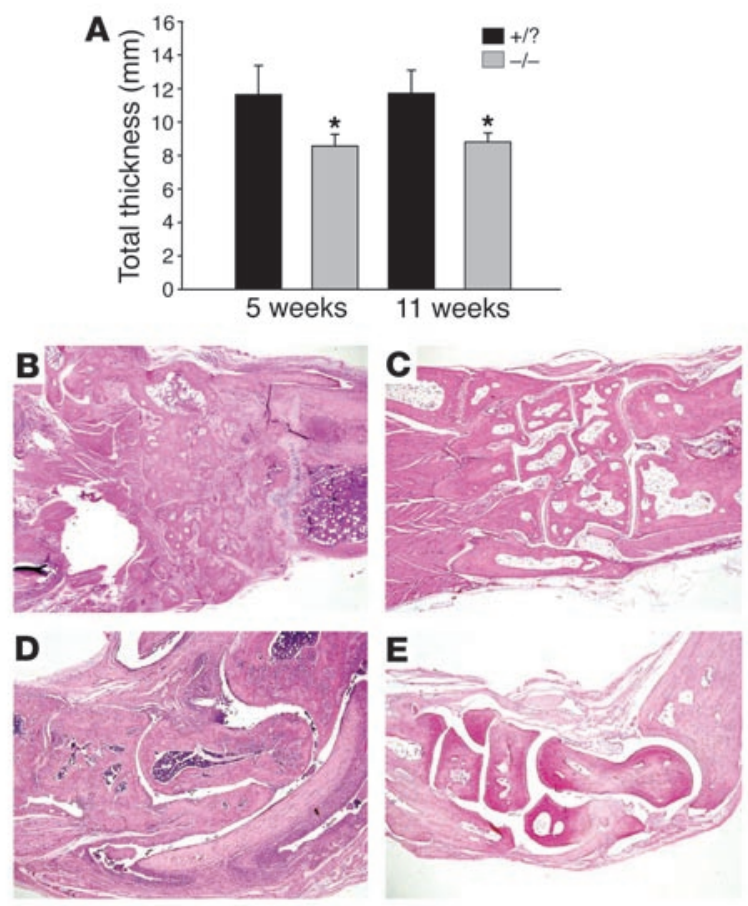

\section{Figure 4}

Spontaneous K/BxN arthritis. Nik ${ }^{-1-}$ mice and control littermates were bred to express both the KRN T cell receptor and $\mathrm{H}-2^{97}$ allele, a combination that leads to severe spontaneous arthritis in wild-type mice, apparent by 5 weeks. (A) Total paw thickness (sum of results for all 4 paws) in $\mathrm{Nik}^{+/ ?}$ and $\mathrm{Nik}^{-1}$ mice at 5 and 11 weeks of age. ${ }^{*} P<0.0002$ compared with $\mathrm{Nik}^{+?}$ ? (B) Arthritic forepaw from $\mathrm{Nik}^{+/+}$mouse. (C) Nonarthritic forepaw from $\mathrm{Nik}^{-1-}$ mouse. (D) Arthritic hind paw from $\mathrm{Nik}^{+/+}$mouse. (E) Nonarthritic hind paw from $\mathrm{Nik}^{-1}$ mouse. Magnification, $\times 40$. 
of a normal lymph node stroma, we transferred unfractionated splenocytes (containing a mixture of T cells, B cells, and APCs) or mixtures of purified T and B cells, into syngeneic Rag2 $2^{-/-}$hosts. Like SCID mice (40), Rag2 $2^{-/}$mice were resistant to AIA (data not shown). Transfer of $\mathrm{Nik}^{+/ \text {? }}$ splenocytes or purified T cells 1 day prior to first immunization conferred full susceptibility to AIA, while transfer of $\mathrm{Nik}^{-/-}$splenocytes or T cells had no effect, despite equivalent engraftment of $\mathrm{T}$ cells in the recipient spleens. The latter is important because of reports that NIK-defective lymphocytes show defects in homing to lymphoid organs (38). Thus, the failure of $\mathrm{Nik}^{-1-}$ mice to respond to AIA is due to T cell dysfunction. Furthermore, although other model systems have shown at least partial immune reactions in NIK-deficient mice (21-23), the complete resistance of $\mathrm{Nik}^{-/-}$mice to this arthritis model is unique.

In contrast to the acute serum transfer form of the $\mathrm{K} / \mathrm{BxN}$ model, which can be induced on a wide variety of mouse strains, the genetic model, which is spontaneous and chronic, has only been evaluated in crosses of KRN transgenic mice with NOD mice that express H-2g7. Previously, Mandik-Nayak et al. (44) showed that $\mathrm{K} / \mathrm{BxN}$ mice lacking lymph nodes due to in utero exposure to anti-Lt- $\beta$ receptor antibodies showed a delayed and reduced intensity of arthritis, which indicates the importance of lymph nodes in this model. However, our experiments, in which we have bred $\mathrm{Nik}^{-/-}$mice and control littermates to express KRN and $\mathrm{H}-2^{\mathrm{g} 7}$, represent the first report of additional genetic influences. Our findings, based on studies using mice lacking lymph nodes but with additional lymphocyte abnormalities, show a more complete inhibition of arthritis, supporting the previous findings and suggesting additional contributions of the latter cell types.

The difference in the dependence of the AIA and $\mathrm{K} / \mathrm{BxN}$ models on the presence of lymph nodes is interesting. Both models depend on systemic antigen-specific $\mathrm{T}$ and $\mathrm{B}$ lymphocyte responses, although the former is to a foreign antigen, while the latter is to a self antigen. Additionally, AIA induction was performed in animals with a normal $\mathrm{T}$ cell receptor repertoire, while the $\mathrm{K} / \mathrm{BxN}$ model is dependent on the transgenic KRN T cell receptor, which is expressed on all $\mathrm{T}$ cells.

In summary, our results indicate that NIK is critical for antigenmediated induction of arthritis in both AIA and $\mathrm{K} / \mathrm{BxN}$ models. Additionally, NIK controls the pathological induction of osteoclastogenesis in the context of the STA model of inflammatory arthritis.

\section{Methods}

Animals. Nik-/- mice on the 129Sv/Ev background (18) were originally provided by R.D. Schreiber (Washington University, St. Louis, Missouri, USA). $L T-\alpha^{-/-}$and $\mathrm{H}-2^{\mathrm{g} 7}$ mice were from the Jackson Laboratory. Rag $2^{{ }^{-/-}}$mice of $129 \mathrm{~Sv} /$ Ev background and NOD mice were from Taconic. All mice were 8-12 weeks of age at the start of experiments for AIA and 6-9 weeks of age for serum transfer experiments. The genotype for NIK of all mice used was confirmed by PCR analysis of genomic DNA extracted from tail biopsies. Groups of mice designated as $\mathrm{Nik}^{+/ ?}$ include a combination of $\mathrm{Nik}^{+/+}$and $\mathrm{Nik}^{+/-}$mice. No quantitative or qualitative differences in the response of $\mathrm{Ni}^{+/+}$and $\mathrm{Ni}^{+/-}$ mice were noted. $\mathrm{K} / \mathrm{BxN}$ serum pools were prepared from arthritic mice generated by crossing KRN T cell receptor-transgenic mice with NOD mice (29). All experimental protocols were approved by the Institutional Animal Studies Committee at Washington University School of Medicine.

AIA. AIA in mice was established as described previously (30). Briefly, mice were immunized on days 0 and 7 with $100 \mu \mathrm{g}$ mBSA (Sigma-Aldrich) emulsified in $0.1 \mathrm{ml}$ complete Freund's adjuvant (BD) by intradermal injection at the base of tail. At the same time points (i.e., on days 0 and 7) and as an addi- tional adjuvant, $1 \mu \mathrm{g}$ pertussis toxin (List Biological Laboratories Inc.) was injected intraperitoneally. Arthritis was induced at day 21 by intraarticular injection of $100 \mu \mathrm{g}$ of mBSA in $10 \mu \mathrm{l}$ sterile PBS into the right knee, while the left knee was injected with sterile PBS alone. Mice were sacrificed on day 32.

Cell transfer experiments. For splenocyte transfers, cell suspensions were made from pooled spleens, depleted of erythrocytes in red cell removal buffer (154 $\mathrm{mM} \mathrm{NH}_{4} \mathrm{Cl}, 0.1 \mathrm{mM}$ EDTA, $10 \mathrm{mM} \mathrm{NaHCO}_{3}$ ) for 5 minutes, and adjusted to $3 \times 10^{8} / \mathrm{ml}$ in RPMI media. Splenocytes $\left(3 \times 10^{7}\right)$ were injected into the tail vein of nonirradiated $\operatorname{Rag}^{-/-}$mice 1 day before the mBSA immunization protocol for AIA described above was started. In this case, $100 \mathrm{ng}$ pertussis toxin was used. For experiments using mixtures of B and T lymphocytes, splenocyte suspensions from $\mathrm{Nik}^{+/+}$or $\mathrm{Nik}^{-/-}$mice were stained with APC-conjugated $\mathrm{B} 220$ and PE-conjugated CD90 (eBioscience Inc.) and sorted using a MoFlo high-speed flow cytometer (DakoCytomation). Post-sorting flow cytometry showed each population to be more than $99 \%$ free of contaminating B or $\mathrm{T}$ cells. Mixtures of lymphocytes $\left(5 \times 10^{6}\right.$ of each type) were injected by tail vein into Rag $2^{-/-}$recipients, and AIA was induced as for unseparated splenocytes.

Serum transfer model and arthritis scoring. Arthritis was induced by intraperitoneal injection of $250 \mu \mathrm{K} / \mathrm{BxN}$ serum at days 0 , 2, and 7 and 50 $\mu \mathrm{g}$ LPS (E. coli 011:B4; Sigma-Aldrich) on day 2. A clinical index was used to evaluate paws over time ( 1 point for each affected paw; 0.5 points for a paw with only mild swelling/redness or only a few digits affected) (34). Ankle thickness was measured by dial gauge (Mitutoyo). Both clinical index and ankle thickness were assessed in a blinded fashion.

Histological grading of arthritis. Mice were sacrificed, and the hind paws or whole knees were dissected and fixed in $10 \%$ buffered formalin overnight at $4{ }^{\circ} \mathrm{C}$. Fixed tissues were decalcified for 10-14 days in $14 \%$ EDTA, dehydrated, and embedded in paraffin. Sagittal sections $(5 \mu \mathrm{m})$ were stained with H\&E or TRAP. Histological sections for the serum transfer model were graded blindly. Inflammation and bone erosion were scored on a scale of 0 to 3 ( 0 , none; 1 , mild; 2 , moderate; 3 , severe).

Measurement of serum TRAP5b activity. Immediately prior to sacrifice, mice were anesthetized and bled retro-orbitally. After clotting and centrifugation, serum was collected at stored at $-80^{\circ} \mathrm{C}$ prior to analysis using the MouseTRAP assay (IDS Inc.) according to the manufacturer's instructions. Samples were tested in duplicate and results compared to the standard curve, and mean values expressed as $\mathrm{U} / \mathrm{l}$ were plotted.

FACS analysis. The spleen cells from transplanted or nontransplanted Rag $2^{-/-}$mice on day 32 were sieved to create single-cell suspensions and washed in RPMI media. Erythrocytes were removed from spleen cell suspensions using red cell removal buffer. Cells $\left(1 \times 10^{6}\right)$ were stained with FITC-conjugated antibody to CD90 (eBioscience Inc.) and analyzed by flow cytometry on a FACScan using CellQuest software (BD).

$R N A$ extraction and semiquantitative RT-PCR. Hind paw ankle joints were isolated from control mice and those at days 3 and 4 of STA, then flash frozen in liquid nitrogen and pulverized using a CertiPrep Freezer/Mill 6750 (SPEX CertiPrep) under liquid nitrogen to achieve a fine powder of approximately $2 \times 1 \times 1 \mathrm{~mm}$. RNA was prepared by extracting the powder with Trizol (Invitrogen Corp.), followed by purification with RNeasy (QIAGEN). For each data point, tissue from 3 animals was pooled. Generation of cDNA and PCR were performed as described previously (26), and the same primers were used for GAPDH. Oligonucleotide primer sequences were: RANKL: sense, 5'-CGTGCAGAAGGAACTGCAACACAT- ${ }^{\prime}$ ' and antisense, 5' -TGACTTTATGGGAACCCGATGGGA-3'; and TNF- $\alpha$ : sense, $5^{\prime}$-AATGGCCTCCCTCTCATCAGTTCT-3' and antisense, 5'-TGAGATAGCAAATCGGCTGACGGT-3'. All reactions were performed at the same time, with the same amount of cDNA, using 24 cycles for GAPDH and 34 cycles for RANKL and TNF- $\alpha$.

$O C$ culture. OCs were cultured from isolated bone marrow-derived macrophages as described previously (26), using recombinant GST-RANKLand M-CSF-containing supernatant. TNF- $\alpha$ was from R\&D Systems. 
K/BxN arthritis. Nik ${ }^{+/-}$mice were crossed with KRN T cell receptor-transgenic mice bearing 2 alleles of the transgene. All offspring were screened by PCR of tail DNA for NIK genotype and to confirm the presence KRN. Separately, $\mathrm{Nik}^{+/-}$mice were crossed with $\mathrm{H}-2^{27}$-transgenic mice, which express $\mathrm{H}-2 \mathrm{~K}^{\mathrm{b}}$. Offspring were screened by PCR for NIK genotype and by flow cytometry of peripheral blood for the presence of the $\mathrm{H}-2^{\mathrm{g} 7}$ allele

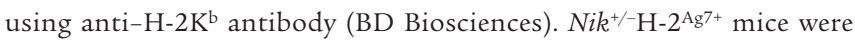
intercrossed, and this second generation was screened for NIK genotype by PCR and for $\mathrm{H}-2 \mathrm{~K}^{\mathrm{b}}$ levels by flow cytometry. $\mathrm{Ni}^{+/-}$mice expressing the highest levels of $\mathrm{H}-2 \mathrm{~K}^{\mathrm{b}}$ were considered possible $\mathrm{H}-2^{\mathrm{g} 7}$ homozygotes, and this was tested by mating them to $\mathrm{H}-2^{27}$-negative mice. If all offspring were $\mathrm{H}-2 \mathrm{~K}^{\mathrm{b}+}$ by flow cytometry, then these animals $\left(\mathrm{Nik}^{+/-} \mathrm{H}-2^{\mathrm{g} / / \mathrm{g}^{7}}\right)$ were used for mating with $\mathrm{Nik}^{+/}-\mathrm{KRN}^{+}$genotype mice. All offspring generated by this strategy carried $\mathrm{H}-2^{\mathrm{g}}{ }^{7}$, approximately half were $\mathrm{KRN}^{+}$, and the NIK genotypes were normally distributed. Front and hind paw thicknesses of $\mathrm{KRN}^{+}$ mice were measured at the ankles by digital gauge.

Statistical analysis. Data are shown as mean \pm SD. Group mean values were compared by unpaired Student's $t$ test. For the serum TRAP5b experiment, in which levels were tested before and after induction of arthritis, the paired Student's $t$ test was used.

1. Pope, R., and Perlman, H. 2000. Rheumatoid arthritis. In Principles of molecular rheumatology. G. Tsokos, editor. Humana Press Inc. Totowa, New Jersey, USA. 325-361.

2. Ruderman, E.M., and Tambar, S. 2004. Psoriatic arthritis: prevalence, diagnosis, and review of therapy for the dermatologist. Dermatol. Clin. 22:477-486.

3. Ritchlin, C.T., Haas-Smith, S.A., Li, P., Hicks, D.G., and Schwarz, E.M. 2003. Mechanisms of TNF- $\alpha-$ and RANKL-mediated osteoclastogenesis and bone resorption in psoriatic arthritis. J. Clin. Invest. 111:821-831. doi:10.1172/JCI200316069.

4. Smith, J., and Haynes, M. 2002. Rheumatoid arthritis - a molecular understanding [review]. Ann. Intern. Med. 136:908-922.

5. Goldring, S. 2002. Pathogenesis of bone erosions in rheumatoid arthritis. Curr. Opin. Rheumatol. 14:406-410.

6. Shigeyama, Y., et al. 2000. Expression of osteoclast differentiation factor in rheumatoid arthritis. Arthritis Rheum. 43:2523-2530.

7. Kong, Y.Y., et al. 1999. Activated T cells regulate bone loss and joint destruction in adjuvant arthritis through osteoprotegerin ligand. Nature. 402:304-309.

8. Pettit, A., et al. 2001. TRANCE/RANKL knockout mice are protected from bone erosion in a serum transfer model of arthritis. Am. J. Pathol. 159:1689-1699.

9. Redlich, K., et al. 2002. Osteoclasts are essential for TNF- $\alpha$-mediated joint destruction. J. Clin. Invest. 110:1419-1427. doi:10.1172/JCI200215582.

10. Li, Q., and Verma, I.M. 2002. NF-КB regulation in the immune system. Nat. Rev. Immunol. 2:725-734.

11. Franzoso, G., et al. 1997. Requirement for NF-кB in osteoclast and B-cell development. Genes Dev. 11:3482-3496.

12. Makarov, S.S. 2001. NF-אB in rheumatoid arthritis: a pivotal regulator of inflammation, hyperplasia, and tissue destruction. Arthritis Res. 4:200-296.

13. Hayden, M.S., and Ghosh, S. 2004. Signaling to NF-кB. Genes Dev. 18:2195-2224.

14. Campbell, I.K., Gerondakis, S., O’Donnell, K., and Wicks, I.P. 2000. Distinct roles for the NF-кB1 (p50) and c-Rel transcription factors in inflammatory arthritis. J. Clin. Invest. 105:1799-1806.

15. Clohisy, J.C., et al. 2003. Direct inhibition of NF-кB blocks bone erosion associated with inflammatory arthritis. J. Immunol. 171:5547-5553.

16. Dai, S., Hiriyama, T., Abbas, S., and Abu-Amer, Y. 2004. The IKK inhibitor, NEMO-binding domain peptide, blocks osteoclastogenesis and bone erosion in inflammatory arthritis. J. Biol. Chem.

\section{Acknowledgments}

We thank Crystal Idleberg, Dorothy Edwards, and Pat Keller for expert animal histology and Paul Allen and Yousef Abu-Amer for critical reading of the manuscript. This work was supported by a grant from the Washington University/Pharmacia Biomedical Program and by NIH grants (AR47846 and AR48335 to D.V. Novack). We thank William Eades and Jacqueline Hughes in the Siteman Cancer Center High Speed Sorter Core Facility for performing cellsorting segments of our experiments. The Siteman Cancer Center is supported in part by National Cancer Institute Cancer Center Support Grant (P30 CA91842).

Received for publication November 27, 2004, and accepted in revised form April 21, 2005.

Address correspondence to: Deborah Veis Novack, Washington University School of Medicine, Division of Bone and Mineral Diseases, 660 South Euclid Avenue, Box 8301, St. Louis, Missouri 63110, USA. Phone: (314) 454-8472; Fax: (314) 454-5047; E-mail: novack@wustl.edu.

279:37219-39222.

17. Jimi, E., et al. 2004. Selective inhibition of NF-кB blocks osteoclastogenesis and prevents inflammatory bone destruction in vivo. Nat. Med. 10:617-624.

18 . Yin, L., et al. 2001. Defective lymphotoxin- $\beta$ receptor-induced NF- $\kappa B$ transcriptional activity in NIKdeficient mice. Science. 291:2162-2165.

19. Miyawaki, S., et al. 1994. A new mutation, aly, that induces a generalized lack of lymph nodes accompanied by immunodeficiency in mice. Eur. J. Immunol. 24:429-434.

20. Futterer, A., Mink, K., Luz, A., Kosco-Vilbois, M.H., and Pfeffer, K. 1998. The lymphotoxin $\beta$ receptor controls organogenesis and affinity maturation in peripheral lymphoid tissues. Immunity. 9:59-70.

21. Korenaga, M., Akimaru, Y., Shamsuzzaman, S., and Hashiguchi, Y. 2001. Impaired protective immunity and $\mathrm{T}$ helper 2 responses in alymphoplasia (aly) mutant mice infected with Trichinella spiralis. Immunology. 102:218-224.

22. Karrer, U., et al. 1997. On the key role of secondary lymphoid organs in antiviral immune responses studies in alymphoplastic (aly/aly) and spleenless (Hox11-/-) mutant mice. J. Exp. Med. 185:2157-2170.

23. Yamada, T., et al. 2000. Abnormal immune function of hemopoietic cells from alymphoplasia (aly) mice, a natural strain with mutant NF-KB-inducing kinase. J. Immunol. 165:804-812.

24. Senftleben, U., et al. 2001. Activation by IKK $\alpha$ of a second, evolutionary conserved, NF- $\mathrm{KB}$ signaling pathway. Science. 293:1495-1499.

25. Claudio, E., Brown, K., Park, S., Wang, H., and Siebenlist, U. 2002. BAFF-induced NEMO-independent processing of NF- $\mathrm{KB} 2$ in maturing B cells. Nat. Immunol. 3:958-965.

26. Novack, D.V., et al. 2003. The IкB function of NF- $\mathrm{KB} 2$ p100 controls stimulated osteoclastogenesis. J. Exp. Med. 198:771-781.

27. Chaisson, M.L., et al. 2004. Osteoclast differentiation is impaired in the absence of inhibitor of kappa B kinase alpha. J. Biol. Chem. 279:54841-54848.

28. Iotsova, V., et al. 1997. Osteopetrosis in mice lacking NF-кB1 and NF-кB2. Nat. Med. 3:1285-1289.

29. Korganow, A., et al. 1999. From systemic T cell selfreactivity to organ-specific autoimmune disease via immunoglobulins. Immunity. 10:451-461.

30. Brackertz, D., Mitchell, G., and Mackay, I. 1977. Antigen-induced arthritis in mice. I. Induction of arthritis in various strains of mice. Arthritis Rheum. 20:841-850.

31. Kouskoff, V., et al. 1996. Organ-specific disease pro- voked by systemic autoimmunity. Cell. 87:811-822.

32. Matsumoto, I., Staub, A., Benoist, C., and Mathis, D. 1999. Arthritis provoked by linked $\mathrm{T}$ and $\mathrm{B}$ cell recognition of a glycolytic enzyme. Science. 286:1732-1735.

33. Wipke, B.T., and Allen, P.M. 2001. Essential role of neutrophils in the initiation and progression of a murine model of rheumatoid arthritis. J. Immunology. 167:1601-1608.

34. Ji, H., et al. 2001. Genetic influence on the end-stage effector phase of arthritis. J. Exp. Med. 194:321-330.

35. Smith, C., et al. 2001. NF-KB-inducing kinase is dispensable for activation of NF- $\mathrm{KB}$ in inflammatory settings but essential for lymphotoxin $\beta$ receptor activation of NF- $\mathrm{BB}$ in primary human fibroblasts. J. Immunology. 167:5895-5903.

36. De Togni, P., et al. 1994. Abnormal development of peripheral lymphoid organs in mice deficient in lymphotoxin. Science. 264:703-707.

37. Banks, T., et al. 1995. Lymphotoxin- $\alpha$-deficient mice: effects on secondary lymphoid organ development and humoral immune responsiveness. J. Immunology. 155:1685-1693.

38. Fagarasan, S., et al. 2000. Alymphoplasia (aly)-type nuclear factor $\kappa \mathrm{B}$-inducing kinase (NIK) causes defects in secondary lymphoid tissue chemokine receptor signaling and homing of peritoneal cells to the gut-associated lymphatic tissue system. J. Exp. Med. 191:1477-1486.

39. Carlsen, H., Moskaug, J.O., Fromm, S.H., and Blomhoff, R. 2002. In vivo imaging of NF- $\kappa B$ activity. J. Immunol. 168:1441-1446.

40. Petrow, P.K., Thoss, K., Katenkamp, D., and Brauer, R. 1996. Adoptive transfer of susceptibility to antigen-induced arthritis into severe combined immunodeficient (SCID) mice: role of CD4+ and CD8+ $\mathrm{T}$ cells. Immunol. Invest. 25:341-353.

41. Pohlers, D., et al. 2004. Anti-CD4 monoclonal antibody treatment in acute and early chronic antigeninduced arthritis: influence on Thelper cell activation. Clin. Exp. Immunol. 135:409-415.

42. Matsumoto, M., et al. 1996. Affinity maturation without germinal centres in lymphotoxin- $\alpha$-deficient mice. Nature. 382:462-466.

43. Matsumoto, M., et al. 2002. Essential role of NF-kB-inducing kinase in $\mathrm{T}$ cell activation through the TCR/CD3 pathway. J. Immunol. 169:1151-1158.

44. Mandik-Nayak, L., Wipke, B.T., Shih, F.F., Unanue, E.R., and Allen, P.M. 2002. Despite ubiquitous autoantigen expression, arthritogenic autoantibody response initiates in the local lymph node. Proc. Natl. Acad. Sci. U. S. A. 99:14368-14373. 